\title{
Image Analysis of Zhang Dongsheng in TV Series Cat's Cradle from Psychoanalysis Theory
}

\author{
Yaqian Zhang, Jie Du, Wenqian Zheng* \\ Zhejiang Normal University, Jinhua, China \\ Email: 547079243@qq.com
}

How to cite this paper: Zhang, Y.Q., Du, J. and Zheng, W.Q. (2021) Image Analysis of Zhang Dongsheng in TV Series Cat's Cradle from Psychoanalysis Theory. Open Access Library Journal, 8: e7572.

https://doi.org/10.4236/oalib.1107572

Received: May 23, 2021

Accepted: July 11, 2021

Published: July 14, 2021

Copyright $\odot 2021$ by author(s) and Open Access Library Inc.

This work is licensed under the Creative Commons Attribution International License (CC BY 4.0).

http://creativecommons.org/licenses/by/4.0/

\begin{abstract}
Freud's psychoanalysis mainly includes four parts: the theory of subconscious mind, the theory of personality structure, the development of sexual psychology and psychological defense mechanism. This paper uses the theory of subconsciousness and psychological defense mechanism to analyze the character of Zhang Dongsheng in the TV series Cat's Cradle.
\end{abstract}

\section{Subject Areas}

Psychology

\section{Keywords}

Zhang Dongsheng, Psychoanalysis

\section{Introduction}

In the summer of 2020, iQIYI's self-made suspense online drama Cat's Cradle (adapted from the novel The Bad Kids) has become popular all over the Internet since it was released. With its unique theme and superb acting skills, the play has won a good reputation, with Douban score as high as 8.9. It not only gains the reputation and quality, but also arouses the public's thinking about the human nature of its characters. This paper analyzes the character Zhang Dongsheng by using subconscious theory and psychological defense mechanism.

\section{About Zhang Dongsheng}

Zhang Dongsheng has a dual character. He killed a lot, carrying six people's lives, can be regarded as a "killer". With his parents-in-law hiking mountain 
climbing, after the summit of the two old people together pushed down the cliff; taking advantage of his wife's weakness of anemia, he changed her medication before swimming, resulting in his wife drowning while swimming; Zhu's father, Zhu Yongping, Wang Yao and Wang Li were stabbed to death in a dark and dilapidated aquaculture farm. "The murderous demon" is the most intuitive impression he leaves to the audience. But such a bad guy, he takes $\mathrm{Pu} \mathrm{Pu}$ and Yan Liang to live at home when they have nowhere to go, takes them to KFC, and saves Zhu Chaoyang when he is kidnapped. He is so heinous, but also so helpless, is a contradiction. See the whole play to this person had mixed emotions, should hate its bones, but also can't help to give birth to a feeling of pity for him.

In the strange town, Zhang Dongsheng is just a lonely stranger, is a middle class family in the door son-in-law, he was born poor, middle-aged have accomplished nothing, also is a key university graduate eventually but only in a small town when a side high school guidance teacher, children's palace that married wife's family members were looked down upon his background [1]. He put all the expectations of class rise on his marriage, but the prenuptial agreement will divorce Zhang Dongsheng back to the bottom of the life with nothing, so the marriage and family became the straw he must tightly hold. In Zhang Dongsheng's subconscious, he is inferiority, he did a lot of things to cover up his inferiority, he cared about appearance, it happened that early bald, every day to wear a wig in front of people as if nothing had happened to cover up his bald fact. $\mathrm{He}$ longed to have a complete family, but his marriage was on the verge of dissolution, his wife had an affair, was determined to divorce him, and the rest of his family did not support his marriage. Zhang Dongsheng has always been eager to identify, to find a sense of belonging.

\section{Psychoanalytic Theory}

Freud's psychoanalysis mainly includes four parts: the theory of subconscious mind, the theory of personality structure, the development of sexual psychology and the mechanism of psychological defense. This paper mainly uses two kinds of subconscious theory and psychological defense mechanism to analyze the character image of Zhang Dongsheng. The subconscious theory is the core of Freud's psychoanalysis theory. The subconscious is not easy to be noticed by people, but it always affects the daily behavior of individuals, because it gathers a lot of complex emotions and emotions, including instinctive impulses, repressed pain, traumatic events and repressed desires that are not accepted by the individuals. Psychological defense mechanism is a psychological operation to eliminate the unpleasant emotion from the consciousness level [2]. Since everyone has a tendency to avoid pain and seek pleasure, psychological defense mechanisms often come into play [3].

\section{Character Analysis of Zhang Dongsheng}

Using the theory of subconsciousness and psychological defense mechanism to 
explore Zhang Dongsheng's personality.

\subsection{The subconscious theory of "Do I have a chance?"}

When analyzing people's spiritual world, Freud divides it into three parts: id, ego and superego. The id is the instinctive impulse hidden deep in human heart, representing the most primitive desire to satisfy the instinctive impulse; the ego stands between the id and the superego, representing reason and wit; and the superego is the moral control of the ego. The night before, his parents mentioned that they wanted to travel to Liupeng Mountain. Because of the inconvenience of transportation, Zhang Dongsheng offered to drive his parents there. This was not his premeditated murder. He's asking his father-in-law, "Do I have a chance?" He is hoping to persuade a father-in-law persuaded his wife, he wants is a complete family, then was the father-in-law of refuse, father-in-law said he and his daughter $\mathrm{Xu}$ Jing continue together will not happy, he wanted to escape from the truth at all, but parents suddenly authors fact, broke the good ideal, dong-sheng zhang that he could not self-deception, subconscious inspired his heart, the bottom of my heart to all hate two people, feel that the elimination of them, their marriage seems to be able to continue to sustain. It's also a sign that the id is on the verge of exploding, driving him to push his parents-in-law down a mountain. "Do I still have a chance?" Mr. Zhang asked before each attack. It is also a constant attempt to control the id and keep it from erupting. At the last moment of killing, he threw the initiative to the other party, wanting to give the other party the last chance. He seemed callous, but in fact he still had a glimmer of hope.

\subsection{The "Fear of Loss" in Subconscious Theory}

Zhang Dongsheng and Zhu Chaoyang once said, "Do you have anything you are particularly afraid of losing? Sometimes we do things we don't want to do for these things." "I really understand that we both want to get back to normal as soon as possible. We don't want to lose anything." From these two words can feel in his subconscious mind is that I wish to live a normal life, a lot of motivation is not his original intention, in the family environment under strong pressure to give his heart, the more afraid to lose everything in the same as left him, his heart is helpless, in order to keep the things he CARES about, He used an almost extreme behavior to save his family, towards a road of no return.

\subsection{The Inner Changes of Zhang Dongsheng under the Theory of Subconsciousness}

The "good" in Zhang Dongsheng's heart slowly awakes in the association with three children. Yan Liang and $\mathrm{Pu} \mathrm{Pu}$ because the typhoon did not leave, live in Zhang Dongsheng home, slowly Zhang Dongsheng was affected by the innocence of the children in the heart, $\mathrm{Pu} \mathrm{Pu}$ for him when he put a band aid, he seemed to be touched the bottom of my heart the most soft part, like a father put 
all the tenderness to $\mathrm{Pu} \mathrm{Pu}$, hope that everything can come back, back to normal life. Now, like a group of people who have gone to the edge of a precipice, they seem to turn around and return safely. However, Zhu Chaoyang and Yan Liang in the toilet to talk about the copy of the card was heard by Zhang Dongsheng, resulting in a series of changes, and eventually took them down the cliff. Zhang Dongsheng feels after one of his efforts, the life is still unable to be as it wishes, inspired the subconscious of his heart, carry out a series of crazy revenge. The three children "malicious" once again exposed as the last straw of Zhang Dongsheng's human bottom line. At the end of the film, Zhang Dongsheng is ready to kill Zhu Chaoyang. At this time, he has completely become a moral and insensitive Zhang Dongsheng. The highest thought belongs to the superego and represents the ideal of the good, because it is fully moral and doctrinal, whereas the lowest thought belongs to the id and embodies the most primitive desires. Through the comparison between the id and the superego, it can be found that his inner world is changing step by step. Finally, the id breaks through the bondage of the superego and commandeers Zhang Dongsheng's body.

\subsection{The Psychological Defense Mechanism Is Not Willing to Face the Fact of Baldness}

There were several such scenes in the TV series: in the bathroom, Zhang Dongsheng faced the mirror alone and took off his wig. He would stare at the young bald man in the mirror coldly. His eyes were indifferent, as if he were looking at an irrelevant stranger who did not want to face the fact that he was bald. Only in the dark place of the bathroom would he take off his wig to see him as he really was, but his indifferent eyes could feel that he was in denial of what he looked like in the mirror and did not want to face it. This was his psychological defense mechanism at work.

\section{Conclusions}

In general, the line between good and evil is not so clear. Zhang Dongsheng is not a nefarious person, his meticulous treatment of his wife, but his wife still did not give him a chance, that he had to pay everything to love the object, now has betrayed him, he can not accept the fact that his marriage failed, and finally killed his wife. When people do not have a little emotional support, it is easy to go to extremes, either you die or I die; he cared about $\mathrm{Pu} \mathrm{Pu}$, when he knew $\mathrm{Pu}$ $\mathrm{Pu}$ wanted money after the intention, really moved the heart of compassion, so as to save Zhu Chaoyang who had no friends with him. Zhang Dongsheng could not face his real life, just as he tried to hide his bald head. Love in a hopeless marriage, dong-sheng zhang corked gradually, has become a will own all exist in a false representation and distortion of the ethereal hopes obsession, originally he just want to use the death of my father-in-law the heart of his wife, but later become the development trend of he can't control, he is a complete contradiction [4]. 
Through the description of Zhang Dongsheng, the TV drama Cat's Cradle explores the desire and impulse in the human subconscious, and reveals the contradiction between the inner world and external behavior of the character by describing the confrontation between the character's "id", "ego" and "superego". The film not only shows the complexity of human nature, but also expresses the class contradictions and dark side of the current society. Through Zhang Dongsheng, a typical character who gradually declines and goes on the road of no return, it reflects the coordinated choice among "id", "ego" and "superego" that people show in the face of out-of-control life.

Human nature is complex, and every person's character is inseparable from the environment in which he grew up or lived. There is sunshine in the heart of the worst man, and there is darkness in the heart of the best man. It is difficult for us to judge the quality of Zhang Dongsheng, as said in the play, "If you want to believe in fairy tales, the world is full of beauty; if you choose to believe in reality, the world is full of hardships" [5] combined various behaviors of Zhang Dongsheng with psychoanalysis theory to deeply understand and analyze, and also provided more reasonable.

\section{Conflicts of Interest}

The authors declare no conflicts of interest.

\section{References}

[1] Lin, X. (2020) Secret Corner: The Birth and Suppression of Evil. Arts Criticism, 18, 87-96.

[2] Blackman, J. (2011) Mask of Mind (101 Kinds of Psychological Defense). East China Normal University Press, Shanghai, 1-21.

[3] Xu, S.X. and Zhang, R.X. (2018) Analysis of Sexual Psychology and Sex Education of Minors with Subconscious Theory. Journal of Campus Life \& Mental Health, 16, 378-380.

[4] Wu, A.B. (2004) Ethical Significance Analysis of Freud's Personality Structure Theory. Journal of Karamay, 18, 7-9. (In Chinese)

[5] Xie, Z.J. (2020) Goodness and Evilness of Human Nature-Adaptation from Mystery "Cat's Cradle" to Novel "The Bad Kids". Journal of Hubei Industrial Polytechnic, 33, 71-75. 